Article

\title{
Hybrid CHP/Geothermal Borehole System for Multi-Family Building in Heating Dominated Climates
}

\author{
Saeed Alqaed ${ }^{1}$, Jawed Mustafa ${ }^{1, *}\left(\mathbb{0}\right.$, Kevin P. Hallinan ${ }^{2}\left(\mathbb{D}\right.$ and Rodwan Elhashmi ${ }^{2}$ \\ 1 Mechanical Engineering Department, College of Engineering, Najran University, Najran 61441, Saudi Arabia; \\ saalqaed@nu.edu.sa \\ 2 Department of Mechanical \& Aerospace Engineering, University of Dayton, Dayton, OH 45469-0238, USA; \\ kevin.hallinan@udayton.edu (K.P.H.); elhashmir1@udayton.edu (R.E.) \\ * Correspondence: jmmustafa@nu.edu.sa; Tel.: +966-534875470
}

Received: 7 August 2020; Accepted: 17 September 2020; Published: 20 September 2020

check for updates

\begin{abstract}
A conventional ground-coupled heat pump (GCHP) can be used to supplement heat rejection or extraction, creating a hybrid system that is cost-effective for certainly unbalanced climes. This research explores the possibility for a hybrid GCHP to use excess heat from a combined heat power (CHP) unit of natural gas in a heating-dominated environment for smart cities. A design for a multi-family residential building is considered, with a CHP sized to meet the average electrical load of the building. The constant electric output of the CHP is used directly, stored for later use in a battery, or sold back to the grid. Part of the thermal output provides the building with hot water, and the rest is channeled into the GCHP borehole array to support the building's large heating needs. Consumption and weather data are used to predict hourly loads over a year for a specific multi-family residence. Simulations of the energies exchanged between system components are performed, and a cost model is minimized over CHP size, battery storage capacity, number of boreholes, and depth of the borehole. Results indicate a greater cost advantage for the design in a severely heated (Canada) climate than in a moderately imbalanced (Ohio) climate.
\end{abstract}

Keywords: combined heat and power; smart cities; energy efficient; ground-coupled heat pump; storage capacity; multi-family residence

\section{Introduction}

Multi-family housing energy consumption represents a significant fraction of the total residential energy consumption in the US, about $33 \%$ of the population resides in about 500,000 multifamily buildings. The overall utilization of domestic resources for this division of structures is reported at nearly 15 percent [1]. In addition, these buildings have been shown to be significantly less efficient than owner-occupied homes or rented single-family homes. A recent study documents that rental multi-family residences have energy intensities that are $37 \%$ higher than for owner-occupied multi-family units (i.e., condos or co-ops), $41 \%$ higher than for renter-occupied single family detached units, and $76 \%$ higher than in owner-occupied single family detached units [2]. Greater energy utilization can occur for multiple reasons. The primary reason is that occupants who pay rent with incorporated power expenses have no incentive to preserve resources. Generally, renters will be more motivated to manage their energy expenses if they are responsible for paying their own utilities themselves [3]. Furthermore, owners of the rental properties do not participate in advances to provide more effective energy improvements, especially if renters are responsible for these utilities, as they would not reap the benefits of these savings. 
According to the American Council for Energy-Efficient Economy, there is immediate potential to improve energy efficiency of multi-family buildings in the US by $30 \%$, thereby significantly reducing $\mathrm{CO}_{2}$ emissions and saving an estimated total of 3.443 billion USD in energy costs yearly [4]. Informative curriculums are available for landlord/owners about making improvements to their energy systems and incentives are often offered to motivate these initiatives of lower energy costs [5]. In the U.S., residential multi-family building sector is the least energy-efficient in the country. Borehole storage of solar thermal energy could be a cost-effective way to save both energy and carbon. The study proposed that for both retrofit and new construction for a multi-family residence in the Midwestern United States, where the climate is moderately cold with very warm summers, a district solar borehole thermal solar energy storage (BTES) system. The study claims that an optimal system could achieve an internal return rate (IRR) of $11 \%$ while reducing apartment-wide energy and $\mathrm{CO}_{2}$ consumption by $46 \%$ [6].

\subsection{Combined Heat and Power}

To help reduce the production of greenhouse gases and increase the proficiency of energy resources, the combined heat and power (CHP) systems would be a potential prospect for multi-family structures. These are commonly combustion turbine or reciprocating engine units, located on-site, which turn a generator and have heat recovery systems. CHP's can provide an almost uninterrupted source of electricity and heat, and they have been shown to enhance productivity and decrease the release of carbon dioxide [7]. Unused thermal resources are a result of electricity produced with outdated power sources. CHP devices are also more efficient because they are located close to where both thermal and electrical energy is needed, negating transmission losses. In 2011, natural gas supplied in the electrical power sector of the United States accounted for $7.9 \%$ of produced electrical energy, and there were $43 \mathrm{GW}$ of CHP capacity [8]. A new power and heat generation system is proposed to better exploit the heat content of flue gases from CHP (combined heating and power) systems using sulfur compounds. Due to the reduced final temperature of the exhaust gases (from $140{ }^{\circ} \mathrm{C}$ to $50{ }^{\circ} \mathrm{C}$ ), it is possible to recover a higher amount of heat in the flue gas and remove most of the sulfur emissions to the environment. The study results of the entire system show that the novel system is making better use of the flue gases. The total efficiencies of thermal (first law efficiency) and exergy (second law efficiency) are equal to $82.7 \%$ and $28.8 \%$, respectively [9].

In the US, most of the CHP power is used by large industries, although there is potential for growth of small-scale systems to power individual buildings such as hotels, universities, apartments, condos, and alternate structures where there is balanced energy requirement between year round water heating and electricity, a perfect condition for deploying CHPs. To encourage more favorability of CHP technology and to engage federal and state guidelines in the US, more studies and advancements on the presentation of CHP systems are essential, and furthermore, offering tax motivations along with a suitable monitoring environment could encourage further ventures for domestic locales [10]. To remit the produced electrical power that supplies efficient and heated energy, a scientific model is established for employing the CHP system [11]. Lowering energy rates and enhancing the transmitted power is how this design functions. In comparison to merely utilizing traditional grid power, the findings of this model display an overall yearly rate reduction of $23 \%$ and decreases greenhouse gases by $32 \%$. The model also proposes the best possible CHP size with complex limitations such as energy costs, electrical power, taxes, and unnecessary electricity from the CHP retailed back to the network [12].

For application to multi-family residential buildings, the thermal energy output from a CHP can be used for heating, providing hot-water, or cooling the building if it is used in conjunction with an absorption refrigeration unit. However, in cold climates, the thermal power requirements (heating plus hot water) can dominate electricity demand. This work explores the possibility of integrating a CHP with a ground-coupled heat pump (GCHP) for a multifamily residence. The GCHP serves to meet a large part of the heating and cooling demand, while the CHP supplies electrical energy and heat for hot water. In this hybrid system, excess thermal energy from the CHP can be passed to the GCHP 
for earth storage. This energy can then be extracted during winter months to address the increased heating loads in the winter.

\subsection{Geothermal Vertical Heat Exchanger}

The ground-coupling heat pump (GCHP) systems are becoming attractive air conditioning systems in some regions. The disadvantage is its high initial cost. On the annual basis this GCHP system repels more energy into the ground than the energy extracted from the ground for cooling-dominated buildings. This imbalance can cause system performance to degrade. The study results show that proper HGCHP (hybrid ground-coupled heat pump) systems can effectively reduce both the initial and operating costs [13]. Space heating and cooling can be improved with more proficiency with GCHP systems by utilizing the earth as a heat supply. The earth provides temperatures for cooling that are lower than the ambient air temperatures in summer, and temperatures for heating that are higher than the ambient air temperatures in winter. A large number of GCHP systems have been used in residential and commercial buildings due to their higher efficiency and lower environmental impact [14]. The SGSHPS (solar-ground source heat pump system) worked in various modes of dual heat source coupling and its thermal performance was tested experimentally. The study shows that the collector area and ground heat exchanger (GHE) number have obvious effect on the efficiency of the device, but the impact of the volume of the water tank is very limited. The average coefficient of performance (COP) unit and collection performance for ground intermittent and continuous heat storage mode are $3.65 \%$ and $47.9 \%, 3.8 \%$ and $41.5 \%$, respectively. The evaporator's inlet water temperature in GSHP's daytime stop mode is $1.85 \mathrm{C}$ higher than GSHP's daytime operating mode, and the average unit COP is $3.43 \%$ and $34.8 \%$ [15].

One of the most significant ground properties is its undisturbed temperature. For heating applications, a higher ground temperature leads to a more efficient system, and for cooling applications a lower ground temperature is better. However, a range of temperatures is useful for both applications throughout the year. Over many years, it is possible for the ground temperature in a borehole field to gradually increase or decrease, depending on which load (cooling or heating) is greater on average. This gradual temperature change can degrade the performance of the system.

In GCHP systems with a large imbalance between the heating and cooling loads, it is possible to add other components that can extract or reject heat to the ground, to offset the imbalance. For example, if cooling is the dominant load, then the ground temperature could rise over time, which would degrade the cooling performance of the system. To offset this imbalance, it is necessary to extract excess heat from the ground, which could be achieved with a cooling tower or a solar collector array that circulates the medium fluid and radiates heat to the atmosphere [16]. If the heating load is dominant, it is possible to pass supplemental heat to the ground from a heat source. Systems that have such additional heat rejection or extraction components are known as hybrid GCHP systems. The advantage of a hybrid arrangement is that it serves to reduce the GCHP size and cost in heating or cooling dominated climates [16].

In this research, a hybrid GCHP system that uses supplemental heat from a CHP is considered for a heating-dominated application. The electrical output from the CHP is applied towards the building electrical load, and the CHP thermal output satisfies hot-water demand. Excess thermal energy beyond that required for water heating will be passed into a vertical borehole heat exchanger in order to balance the annual GCHP thermal loads. Furthermore, excess electrical generation is stored in batteries for later use or is sold back to the grid. Grid power is used as necessary for the electrical load during times of high demand.

This system has the potential to lower cost in several ways: by reducing grid power purchases, by improving heating and cooling efficiency with a GCHP, and by reducing the necessary size of the GCHP system as a result of using excess CHP heat to balance annual ground storage thermal loads. 


\subsection{Objectives}

Achievability will be validated for a multi-family residential building in a heating-dominated climate by researching a hybrid GCHP system with supplemental CHP heat. A model is developed for each system component, as well as an algorithm to determine hourly energy transfers between components (thermal or electric). Three component sizes (GCHP borehole length, CHP rated output, and battery capacity) are adjusted to minimize the system's annual cost, under the constraints of zero annual net grid purchases and balancing of the thermal loads to the ground. Two different climates are examined for the optimized system: one that is slightly dominated by heating (Ohio) and one that is severely dominated by heating (Canada). Ohio's climate is humid continental climate comes under $\mathrm{Dfb}$ and Canada comes under Dfc on Koppen climate classification [17].

\section{Methodology}

Figure 1 provides a hybrid system schematic as an integral part of a multi-family residence. For the sake of getting the CHP's greatest advantages, continuous operation is assumed. The dispatching of electrical output from CHP is prioritized to meet building demands directly. For later use by the building, any excess power generated is first dispatched to the battery, and if the battery is fully charged, the excess power is sold back to the utility grid. Similarly, CHP thermal energy is given priority in meeting the demand for hot water. Any remaining thermal energy is transmitted through a heat exchanger labeled HX to the vertical boreholes. The geothermal heat pump (HP) is used to extract or discharge heat from the boreholes to heat or cool the building.

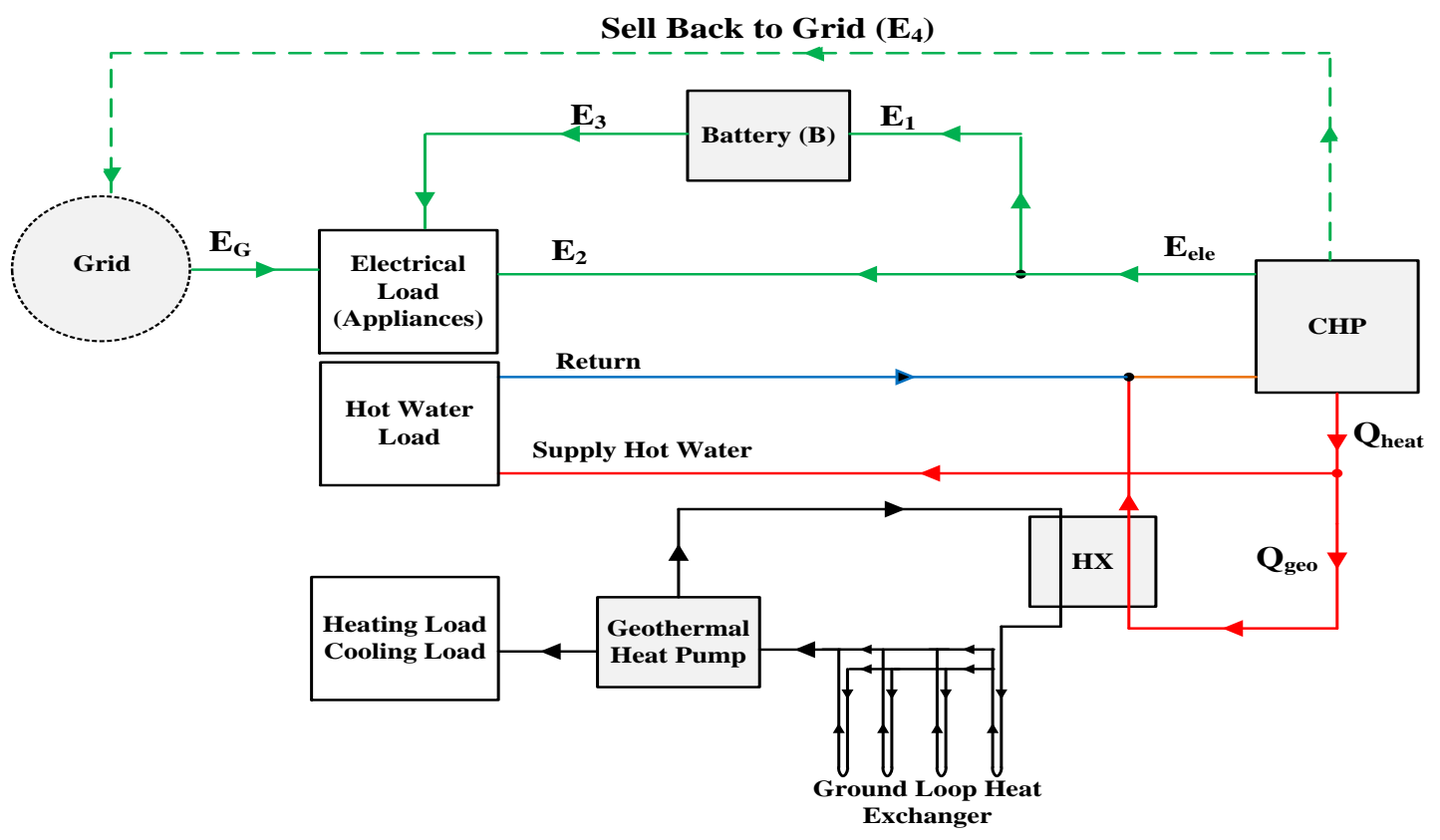

Figure 1. Energy flow diagram of multifamily combined heat power (CHP) and geothermal vertical heat exchange system design.

\subsection{Load Profile Estimation}

There are two weather conditions for deliberation analysis (Columbus, Ohio in the US, and Winnipeg in Canada), so this collective system can be evaluated for potential implementation from both cost and carbon viewpoints in heating-controlled environments. The Columbus site consisted of 120 all-electric apartments of different sizes, built-in 2008 to minimum lighting, appliances, and heating, ventilating and air conditioning (HVAC) efficiency codes. Previously, baseline energy use was established for this complex, including estimation of the hourly aggregate energy use for heating, cooling, water heating, and all other appliances and devices [5]. 
The disaggregated energy consumption components are illustrated hourly in Figure 2 over the course of a whole year. Figure 2 a shows the baseline, weather-independent electrical demand associated with appliances and lighting, and Figure $2 \mathrm{~b}$ shows hourly hot-water demand. Figure $2 \mathrm{c}$ shows the hourly heating and cooling loads.
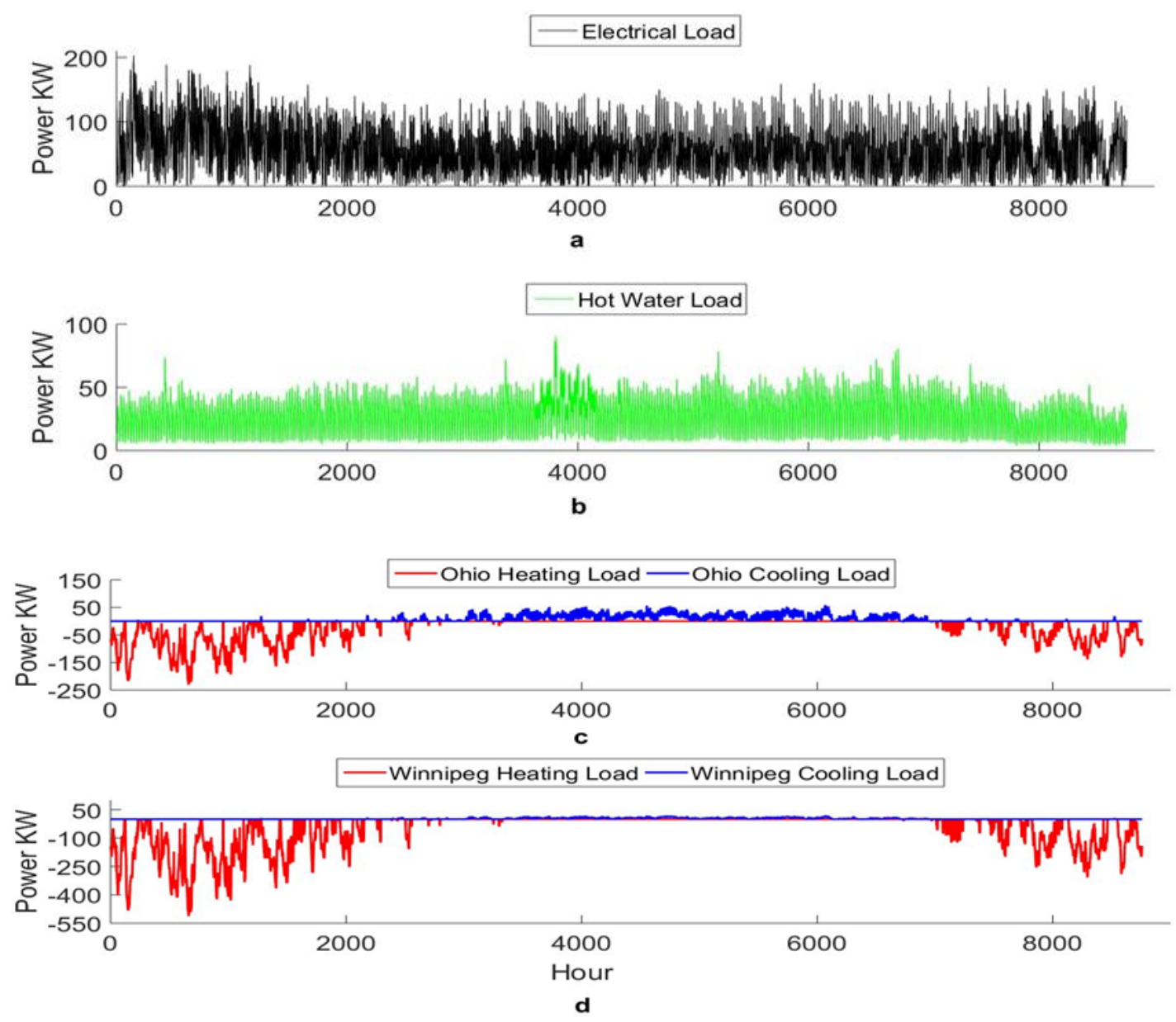

Figure 2. Aggregate hourly building loads (a) electrical, (b) hot-water, (c) heating/cooling for Ohio, and (d) heating/cooling for Winnipeg.

Heating and cooling demand data for Winnipeg are constructed from the Ohio heating and cooling demand data by scaling the Ohio data by the ratio of the degree-day values (Canada to Ohio). The result of this is shown in Figure $2 \mathrm{~d}$, where the heating and cooling loads are, respectively, less than the Ohio data [18].

\subsection{Power Dispatching}

As shown in Figure 1, the electrical side of the system requires a dispatching algorithm, which allocates electrical power to $\mathrm{CHP}$, decides when to discharge the battery or use grid power, and decides when to sell back additional energy to the network. At all times, the dispatching is governed by the level of residential electrical load and battery storage charge. If the electrical load of the building exceeds the electrical output of the $\mathrm{CHP}$, all of the electrical power of the CHP is dispatched to the building and the battery satisfies the rest, if possible. Grid power is used when the load cannot be met by the CHP and battery. If the CHP electrical output exceeds the load, then if the battery is fully charged, the excess CHP power is stored in the battery or is sold back to the grid.

The input energy from natural gas to the CHP per hour is denoted by $S(\mathrm{~kJ} / \mathrm{h})$ and is considered constant for continuous operation. This input energy is divided into an electrical component $S_{E}=\eta_{E} S$ 
and a thermal component $S_{H}=\eta_{H} S$, where efficiencies $\eta_{E}$ and $\eta_{H}$ are the fractions of the input energy converted into electricity and heat, respectively. For each hour $k$, the electrical energy output from the $\mathrm{CHP}, S_{E}$, is dispatched to: support the building load, $E_{2}(k)$, charge the battery, $E_{1}(k)$, or be sold back to the grid, $E_{4}(k)$. This dispatching action requires that:

$$
S_{E}=E_{1}(k)+E_{2}(k)+E_{4}(k)
$$

The electrical load for the apartment complex must be satisfied at each hour, from the electrical energy coming from the CHP, $E_{2}(k)$, from energy dispatched from the battery, $E_{3}(k)$, or, if these collectively are insufficient, from energy supplied by the grid, $E_{G}(k)$.

$$
L_{E}(k)=E_{3}(k)+E_{2}(k)+E_{G}(k),
$$

The battery charge level is $B(k)$ is updated each hour according to:

$$
B(k)=B(k-1)+E_{1}(k)-E_{3}(k) .
$$

Lastly, the battery storage is characterized by three parameters: a maximum storage capacity $B_{\max }$, a minimum storage capacity $B_{L}$, and the number of hours $h$ required to charge or discharge the battery. Therefore, a boundary exists on the hourly energy transfers to and from the battery, according to:

$$
\begin{aligned}
& E_{3}(k) \leq \frac{B_{\text {max }}-B_{L}}{h} \\
& E_{3}(k) \leq \frac{B_{\text {max }}-B_{L}}{h}
\end{aligned}
$$

In addition, it is not permitted for the battery to charge and discharge simultaneously, and it is assumed to be $100 \%$ efficient. The dispatching is based on (1) and a few simple rules at each hour. If the building load exceeds the CHP output, all the electrical output from the CHP will be dispatched to the building and the battery will satisfy as much of the remaining load as possible. Grid power is used when the former is not enough to supply the load. If CHP electrical output exceeds the load, then the battery will store as much of the excess CHP power as possible. Any remaining electricity is sold back to the grid. Figures $3-5$ shows how this dispatching algorithm functions. Figure 3 shows how the electrical power output of the CHP is distributed either to the load, battery, or grid, as per (1). The battery charging level is illustrated in Figure 4, along with the power flows to and from the battery. Finally, Figure 5 illustrates the flow of hourly energy into the charge as per (2). Grid power is only used when the battery is at its minimum charge level, such as at $1300 \mathrm{~h}$.

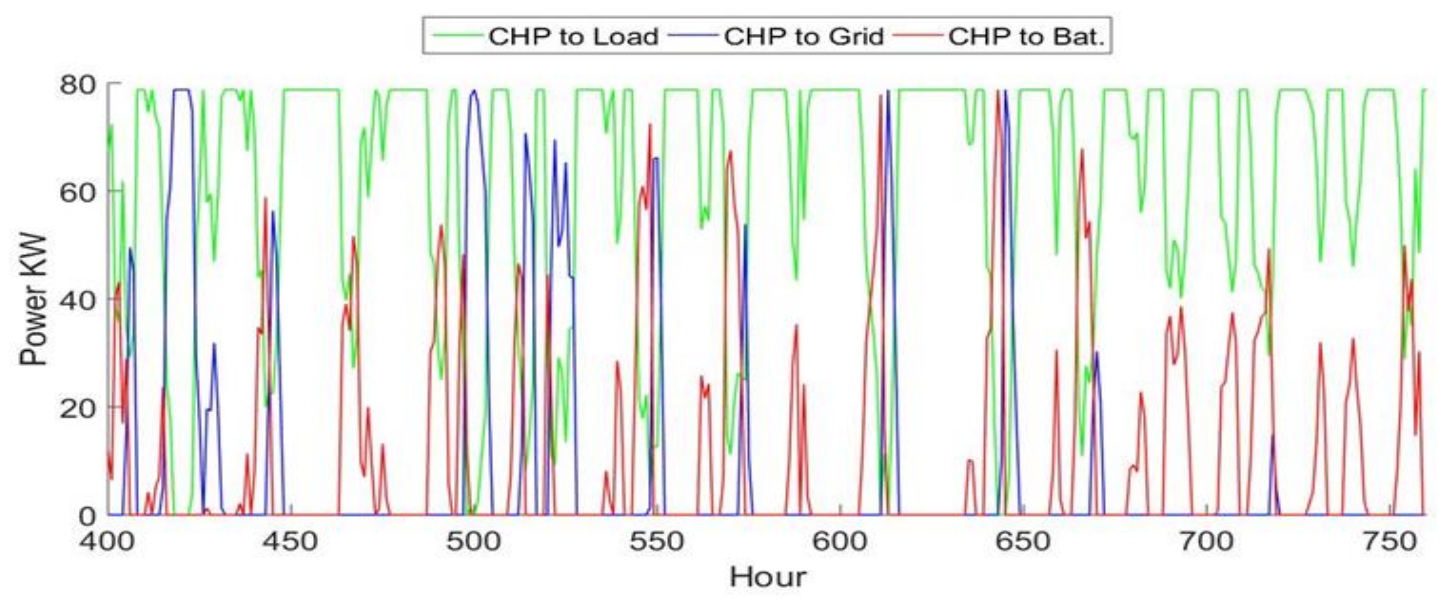

Figure 3. Hourly CHP electrical outputs to the load, battery, and grid. 


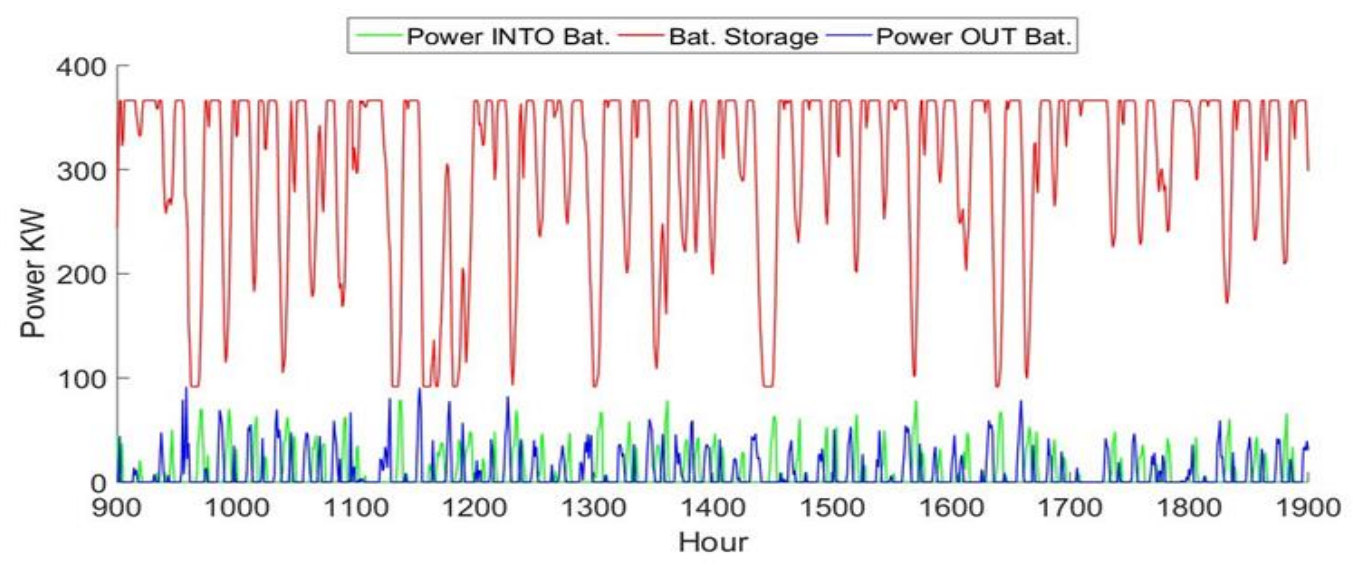

Figure 4. Hourly energy flows in and out of the battery, along with the battery charge level.

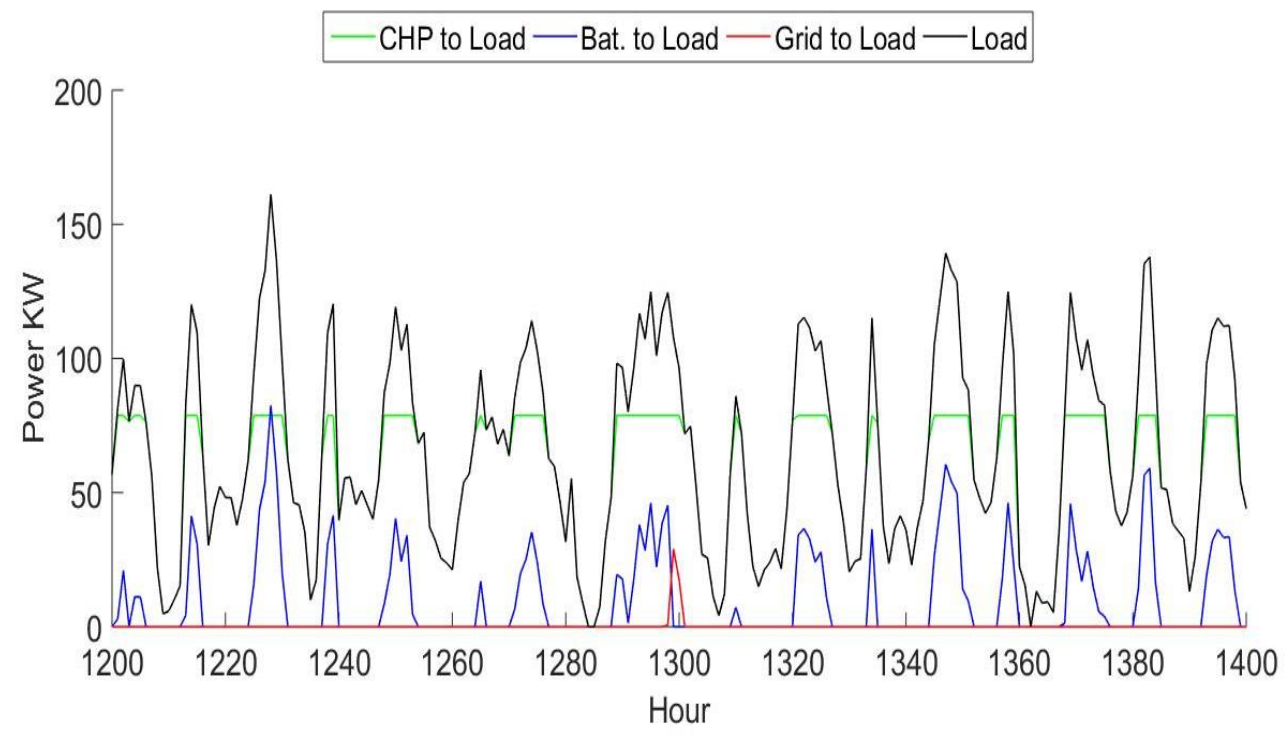

Figure 5. Hourly power flows from the CHP, battery, and grid to satisfy the load.

The CHP thermal output $S_{H}(k)$ is assumed to be always greater than the hot-water load, $L_{H W}(k)$. The remaining thermal energy from the CHP is transferred into the geothermal field through the ground loop heat exchanger, $Q_{\text {geo }}(k)$. Thus,

$$
Q_{\text {geo }}(k)=S_{H}(k)-L_{H W}(k)
$$

The ground loop heat exchanger is assumed to have a constant effectiveness, such that the same percentage of $Q_{\text {geo }}$ is transferred into the boreholes each hour.

\subsection{Borehole Length Calculation}

There has been very little attention given to the effect of different parameter estimation results on the design duration of a borehole heat exchanger. The thermal response was analyzed by using six heat transfer models for the same collection of test data. The relative difference in thermal resistance of the borehole reached $34.4 \%$, and for soil thermal conductivity this value was $11.9 \%$. Software-based approaches have become more susceptible to the impact of parameter estimation for calculating the design duration of the borehole [19].

The GCHP system consists of a rectangular array of uniformly spaced vertical boreholes with a single u-tube in each borehole, each having the same depth. The model for this system treated the array as a single vertical line source [20], using an alternative approach to the Eskilson's g-function, 
a dimensionless temperature response factor that makes it possible to calculate the temperature change at the borehole wall in response to a thermal step input. The modeling objective, implemented in MATLAB, is to determine the optimum number of boreholes along each dimension of the array as well as the optimal depth of the borehole. The earth volume occupied by the array must be large enough to handle heat rejection from the CHP and cooling load and heat extraction due to the heating load. In addition to the loads themselves, key modeling parameters include ground thermal conductivity, combined thermal resistance of borehole piping, medium fluid and grout material, undisturbed ground temperature, and medium fluid mass flow rate. There are two parts to GCHP modeling. First is an optimization of the configuration and length of the borehole for the given heating and cooling loads, as well as the additional heat of the CHP. The second part is a simulation of ground temperatures that arise when using the optimized configuration of the borehole with the specified annual loads. The simulation process of temperature covers the entire lifetime of the system, using a repetition of the same annual load each year.

\subsection{System Cost Model}

This section presents the model for the total cost of the system. This model accounts for: the cost of capital to the CHP, battery, and geothermal systems; the cost of natural gas (NG) needed to operate the CHP; and the purchase and sell-back of net grid electric power. The system is conceived as a retrofit so that the building already has central heating for hot water, which the CHP can supply. The capital costs are treated as investments to be repaid through a fixed-interest loan. For typical weather conditions, determining the NG requirements, electrical purchases, and sell-back requires the simulation of the dispatching model to be run for a full year. Table 1 lists the variables needed to determine the costs for the system.

Table 1. Variables used for calculating annual system cost.

\begin{tabular}{|c|c|c|c|}
\hline Variable & Description & Variable & Description \\
\hline$T_{\text {sys }}$ & System lifetime (years) & $T_{\text {sys }}$ & System lifetime (years) \\
\hline$I$ & Loan interest rate & $I$ & Loan interest rate \\
\hline$g$ & $\begin{array}{c}\text { NG energy } \\
\text { density }(\mathrm{kWh} / \mathrm{kBTU})\end{array}$ & $g$ & $\begin{array}{c}\text { NG energy } \\
\text { density }(\mathrm{kWh} / \mathrm{kBTU})\end{array}$ \\
\hline$C_{N G}$ & NG price $\left(\mathrm{USD} / \mathrm{m}^{3}\right)$ & $C_{N G}$ & NG price $\left(\mathrm{USD} / \mathrm{m}^{3}\right)$ \\
\hline$V_{N G}$ & $\begin{array}{l}\text { NG consumption } \\
\text { (kBTU/month) }\end{array}$ & $V_{N G}$ & $\begin{array}{l}\text { NG consumption } \\
\text { (kBTU/month) }\end{array}$ \\
\hline$H_{m t h}$ & Hours per month (h) & $H_{m t h}$ & Hours per month (h) \\
\hline$P_{\text {tran }}$ & $\begin{array}{l}\text { Grid transmission price } \\
\text { (USD/kWh) }\end{array}$ & $P_{\text {tran }}$ & $\begin{array}{l}\text { Grid transmission price } \\
(\mathrm{USD} / \mathrm{kWh})\end{array}$ \\
\hline$P_{\text {gen }}$ & $\begin{array}{l}\text { Grid generation price } \\
(\mathrm{USD} / \mathrm{kWh})\end{array}$ & $P_{g e n}$ & $\begin{array}{l}\text { Grid generation price } \\
\text { (USD/kWh) }\end{array}$ \\
\hline$H E$ & $\begin{array}{l}\text { Heat exchanger capital } \\
\text { cost (USD) }\end{array}$ & $H E$ & $\begin{array}{c}\text { Heat exchanger capital } \\
\text { cost (USD) }\end{array}$ \\
\hline
\end{tabular}

The full system capital cost is determined by the four largest components of hardware: CHP, batteries, boreholes, and heat exchanger for ground loops. The CHP capital cost is proportional to the electric output rated, $\mathrm{CHP}_{\text {cap }}$. The capital cost of the battery is proportional to its $\mathrm{B}_{\text {cap }}$ storage capacity. The capital cost of the geothermal borehole is calculated per-meter. A federal tax credit, TC, reduces the amount of the loan for the whole system given as follows, using the variables defined in Table 1.

$$
C C_{\text {tot }}=(1-T C) *\left(C C_{C H P} * C H P_{c a p}+C C_{b a t} * B_{c a p}+H E+C C_{g h p} * D_{g h p} * N_{g h p}\right)
$$


The entire system is assumed to operate for a lifetime $T_{S Y S}$, and the loan amount is spread out over this period of time, leading to the following annual loan payment [21].

$$
\text { Annual Loan Payment }=\mathrm{CC}_{\text {tot }} * \frac{I}{1-\frac{1}{(1+I)^{T} S Y S}}
$$

The NG flow rate into the $\mathrm{CHP}$ depends on its rated electrical capacity $\mathrm{CHP}_{\text {cap }}$ and the conversion efficiency, $\eta_{E}$. To obtain the monthly NG volume, this rate is multiplied by the number of hours per month and divided by a factor $g$ to convert $\mathrm{kWh}$ to cubic meters.

$$
V_{N G}=\frac{C H P_{c a p}}{\eta_{E}} \times \frac{H_{m t h}}{g}
$$

Using the cost per unit volume of $C_{N G}$ leads to the following monthly NG cost.

$$
N G \text { Cost }=V_{N G} * C_{N G}
$$

The annual grid cost is found by running the dispatch model for each hour of the year and summing all of the hourly grid energy purchases $E_{G}(k)$ and sell back $E_{4}(k)$ energies. The price for grid energy purchases is a function of the load factor presented to the grid, which is affected by the CHP operation [5]. This price is composed of a generation fee, $P_{\text {gen }}$, and a transmission fee, $P_{\text {tran. }}$. The power rate marketed in return to the grid is also a function of load factor, but sell-back is generally only credited with the generation price. This means that the per-kWh price for grid purchased electricity is higher than the per-kWh sell-back price. The total annual grid purchase and grid-sell back values are computed, and the difference of the two is the net grid purchase cost, as shown in the following equation.

$$
\text { Annual Net Grid Cost }=\left(P_{\text {gen }}+P_{\text {tran }}\right) * \sum_{k} E_{G}(k)-P_{\text {gen }} * \sum_{k} E_{4}(k)
$$

The total annual cost for supplying power to the building is the sum of the annual loan payment, NG purchases, and net grid purchases. The annual NG and net grid costs are found by summing the monthly costs generated using the simulation.

$$
\text { Total Annual Cost }=\text { Loan Payment }+ \text { NG Cost }+ \text { Net Grid Cost }
$$

\subsection{Optimization Process}

The total annual cost of the system is viewed as a nonlinear objective function of the CHP rated electrical output $\mathrm{CHP}_{\text {cap }}$ and the battery storage capacity $\mathrm{B}_{\text {cap. }}$. Over these variables, the cost is minimized. The geothermal component of the cost depends on the total length, which is a function of the $\mathrm{CHP}_{\text {capto }}$ supply the boreholes according to the extra heat available from the $\mathrm{CHP}$. The following steps are required to assess the cost-objective function.

1. The input of the electrical output and storage capacity rated by CHP.

2. Calculate the CHP's annual excess thermal energy by subtracting the total hot-water load from the CHP's total thermal energy.

3. Optimize the size, depth, and borehole spacing of the geothermal borehole array based on the heating and cooling loads and excess thermal energy of CHP, as discussed in Section 2.3.

4. To predict annual NG purchases and net grid purchases, run the CHP electrical dispatching model for one year according to the equations in Section 2.2

5. Evaluate the total system cost using Equations (7)-(12). 
The cost objective function is optimized using the "fmincon" command from MATLAB, which implements quadratic sequential programming to find CHP capacity and battery capacity to minimize the total cost. Furthermore, it is useful to view the cost as a function of CHP capacity while holding battery capacity constant. One possible way to restrict the operation of the system is to set the power sold back to the grid equal in value to the power purchased from the grid, so the net cost of the grid is nil. This target is similar to those set by the US government for the energy consumption of federal buildings in the near future [22].

\section{Results}

\subsection{Minimum Cost with Net Zero Grid Constraint}

For inclusive expense, Combinations of $\mathrm{CHP}$ graded electrical productivity $\mathrm{CHP}_{\text {cap }}$ and battery scope $B_{\text {cap }}$ are examined. Figure 6 shows designs of this expense for both sites, Ohio and Winnipeg, as opposed to CHP cap, for three different battery capabilities. In these designs, a price agreement is specified between the mechanisms of the battery and CHP. With either a higher CHP $(100 \mathrm{~kW})$ and a lower battery $(350 \mathrm{kWh})$ or a higher battery $(450 \mathrm{kWh})$ and a lower $\mathrm{CHP}(75 \mathrm{~kW})$, the lowest possible cost could be achieved. Although the Winnipeg location has a significantly elevated heating capacity, remarkably, if the CHP is the equivalent size, both localities can acquire minimized costs. The CHP sizing for both locations is presumed to be duplicated and established predominantly by the electrical capacity, which is the main reason for this occurrence. When the increased heating capacity stimulates the escalation of the borehole size, a vertical modification in the cost curve is initiated.

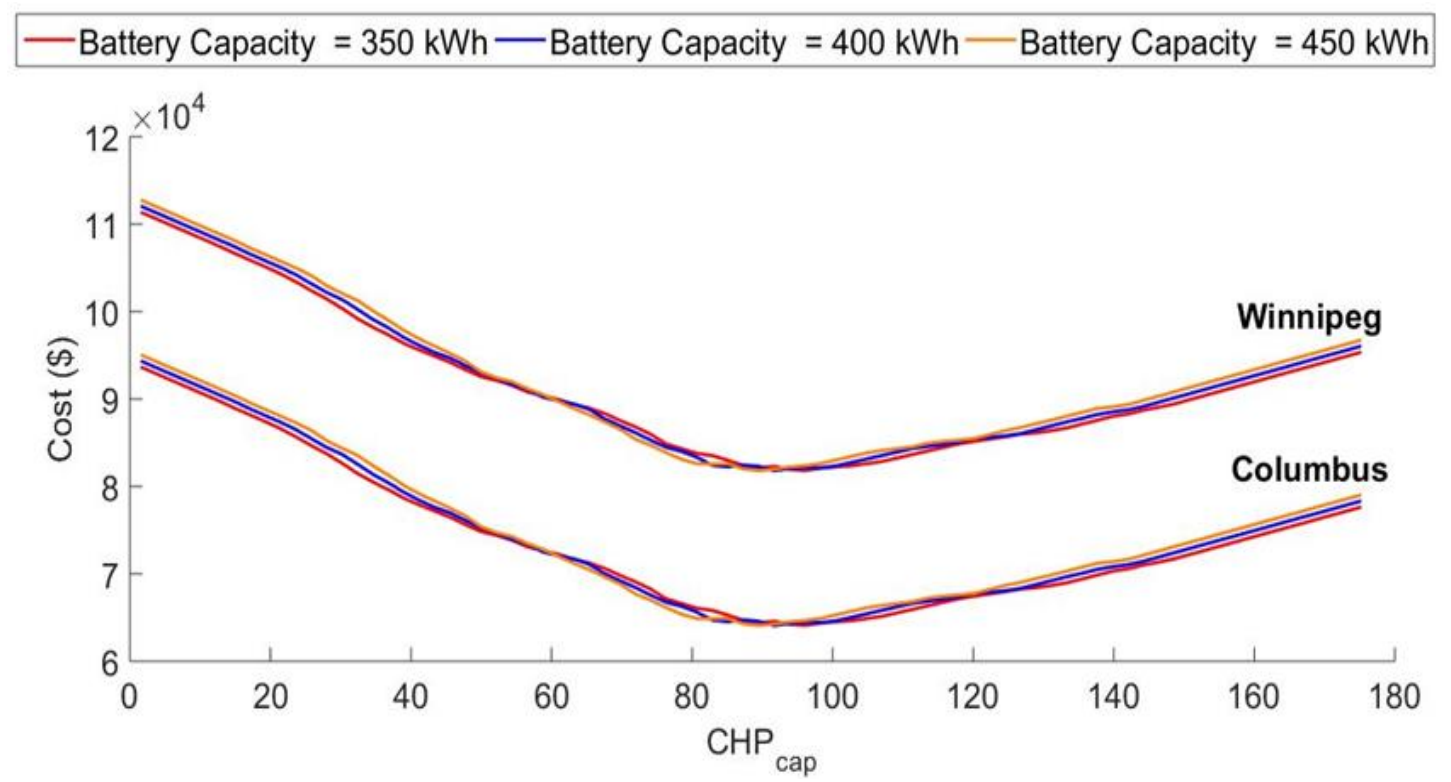

Figure 6. Columbus and Winnipeg total annual costs as a function of CHP size, for three battery capacities.

The results in Figure 6 are produced by no restrictions on the CHP and the battery sizes. If the net-zero network buying limitation is in effect, the battery size successfully becomes the purpose of CHP capability. Exclusively, Figures 7 and 8 show this outcome for Ohio and Winnipeg. In order to minimize the definite transformation between annual grid acquisitions and sell-back, the upper scheme in both figures shows the battery capacity as an essential CHP size purpose. Battery volume declines as a CHP size purpose to sustain the net-zero limitation. When the size of CHP escalates, the costs also escalate, as shown in each figure's middle schemes. In each figure, the bottom scheme shows whether or not the limitation is met. The possibility of coordinating the procurement and sell-back totals is perceivable only for $\mathrm{CHP}$ sizes from about $80 \mathrm{~kW}$ to $100 \mathrm{~kW}$. Under this range, the procurements 
are larger than the sell-back. However, the sell-back exceeds that range of procurements. For both locations, the CHP size, which decreases costs and lends the limit, is about $80 \mathrm{~kW}$. Exclusively, the total minimum annual expenses for Ohio and Winnipeg are roughly 65,000 USD and 83,000 USD.
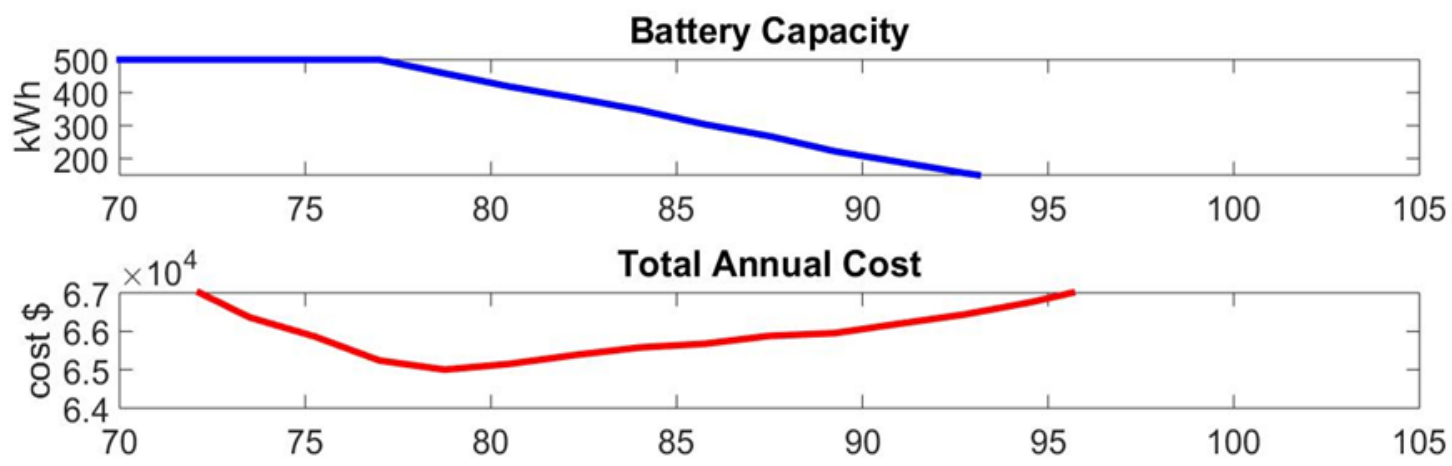

|Purchase - Sell-Back|

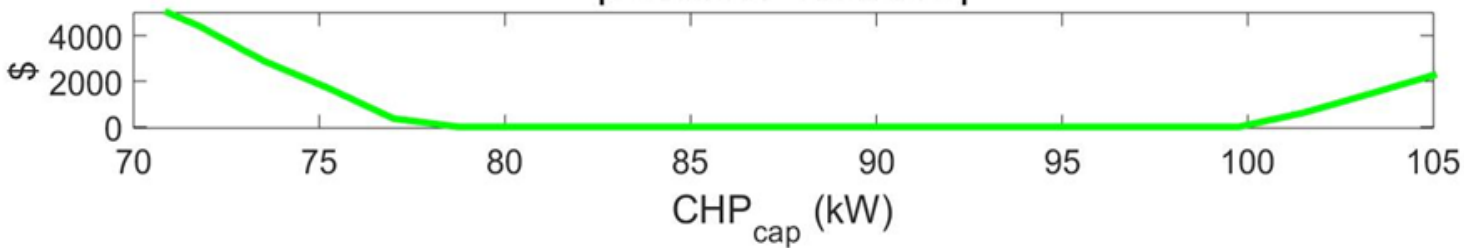

Figure 7. Optimization results for Ohio under the constraint that annual grid purchases are the same as annual grid sell-back.
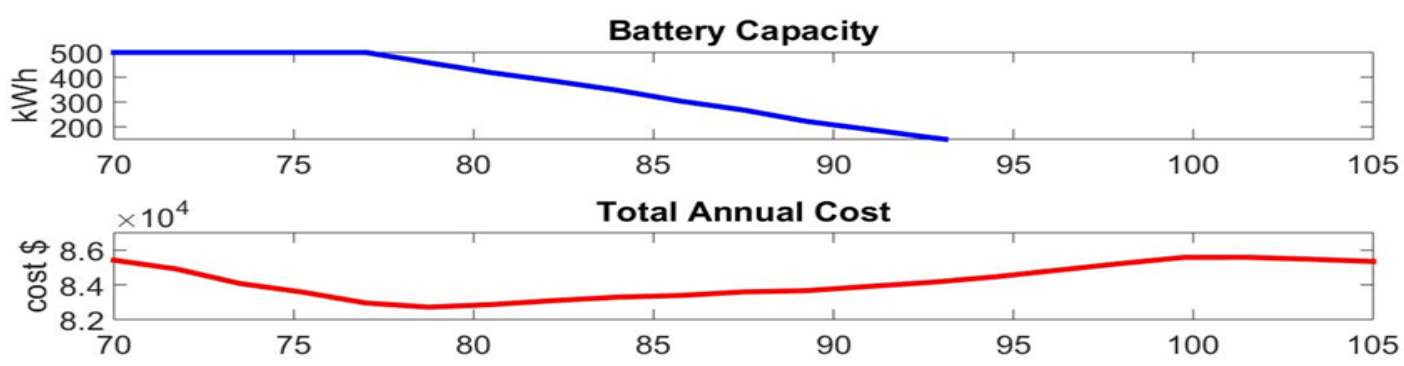

|Purchase - Sell-Back|

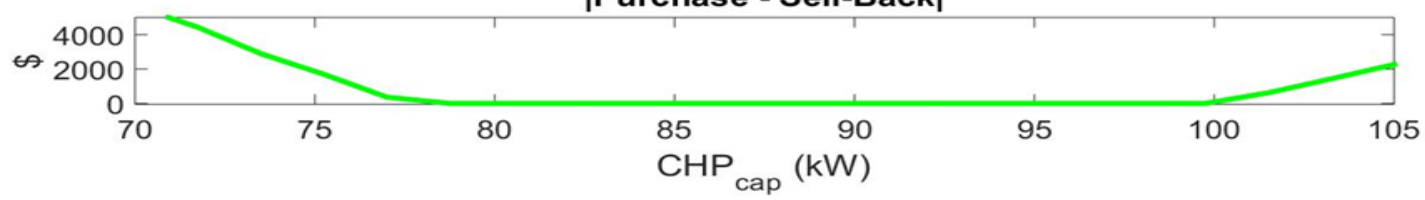

Figure 8. Optimization results for Winnipeg under the constraint that annual grid purchases are the same as annual grid sell-back.

\subsection{Borehole Length and Temperature}

Table 2 illustrates the parameters required to determine the length and temperature of the borehole as a function of the heating load, cooling load, and CHP size. The table presents values for parameters used at the Ohio site. The values used for the location in Winnipeg are the same with the exception of the average earth temperature and thermal conductivity, respectively, $4 \mathrm{C}$ and $1.4 \mathrm{~W} / \mathrm{m}$.C. According to the size of borehole, the range of design flow rate is sufficient to maintain the turbulent flow.

The length optimization process described in Section 2.3 is implemented for different CHP sizes using these parameters and the heating and cooling loads for the two locations. The total cost of the system depends on the optimum length of the borehole, which is a function of the heating and cooling loads and the size of the CHP. It is, therefore, necessary to explore how the depth of the borehole changes regarding the size of the CHP. A CHP size of about $65 \mathrm{~kW}$ produces the shortest borehole 
depth of $60 \mathrm{~m}$ for Ohio, and the shortest borehole depth of $100 \mathrm{~m}$ for Winnipeg is produced by a CHP size of about $80 \mathrm{~kW}$. The colder winter in Winnipeg causes that location to require a significantly greater depth of the borehole than in Ohio. Performing the optimization described in Section 2.3 over a 20-year period on a stand-alone GCHP system, without additional CHP heat, yields the heat pump entering fluid temperatures shown in Figure 9. There are two curves outlined: one for Ohio and one for Winnipeg. A gradual decline in borehole temperature from year to year is evident because the heating load at both locations is larger than the cooling load. Figure 9 shows a minimum designed temperature constraint of $3.9^{\circ} \mathrm{C}$ for Ohio and $-4{ }^{\circ} \mathrm{C}$ for Winnipeg. The progressive decrease in Earth temperature from year to year is evident. For Winnipeg, the imbalance is larger, leading to a greater drop in temperature for that location over time. The temperature in the volume of ground storage has not stabilized even after 20 years of operation. For Winnipeg, the temperature goes negative, so we need antifreeze mixture in this case. The optimized borehole configuration for both locations was $10 \times 10$ boreholes, with a square pattern spacing of $7 \mathrm{~m}$. The depths of the borehole considered on this plot were $120 \mathrm{~m}$ and $210 \mathrm{~m}$, respectively, for locations in Ohio and Winnipeg. The performance of the geothermal heat pumps is based on performance data from major U.S. brand manufacturers as of 2010. The coefficient of performance (COP) of heat pump is determined using a curve fit to two variables: (1) the heat pump entering the temperature of the fluid and (2) the flow rate of the fluid mass. The power consumption on the heat pump is determined by an energy balance. De-superheat is also modeled on output data from the manufacturers. For the heat pump performance, a general categorization is developed based on system efficiency (standard efficiency and high efficiency).

Table 2. Summary of design parameters for Ohio.

\begin{tabular}{cccc}
\hline Variable & Description & Value & Unit \\
\hline Bore Radius & Radius of each borehole & 0.0635 & $\mathrm{M}$ \\
\hline Peak Duration & Time for the maximum load & 6 & $\mathrm{Hrs}$ \\
\hline$T_{g}$ & Average underground earth temperature & 10.88 & $\mathrm{C}$ \\
\hline$K_{g}$ & Average ground thermal conductivity & 1.731 & $\mathrm{~W} / \mathrm{m} \mathrm{C}$ \\
\hline$V H C$ & Average ground volumetric heat capacity & 2.34 & $\mathrm{MJ} / \mathrm{m}^{3} \mathrm{C}$ \\
\hline$\dot{m}$ & Design flow Rate & $0.1262-0.1893$ & $\mathrm{LPS}$ \\
\hline
\end{tabular}

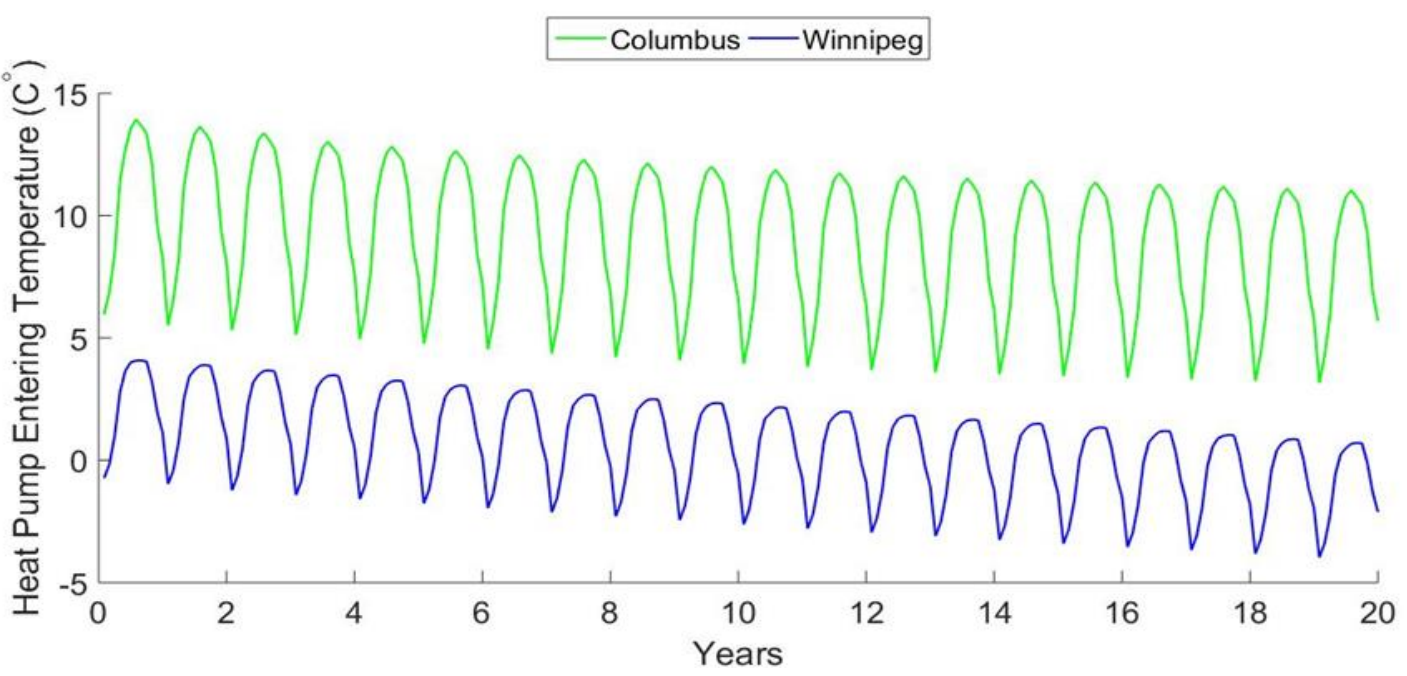

Figure 9. Heat pump entering fluid temperature variation for a stand-alone ground coupled heat pump (GCHP).

The hybrid GCHP system can undertake a portion of this essential surplus energy to stabilize the heating and cooling capacities because the $\mathrm{CHP}$ constantly produces additional thermal energy. Figure 9 
shows the temperature drifts adjustment when the loads are stabilized. The $80 \mathrm{~kW} \mathrm{CHP} \mathrm{is} \mathrm{sufficient} \mathrm{to}$ stabilize the capacities from the $70 \%$ of the existing additional heat for the Ohio locality. Using the same size, CHP will virtually stabilize the capacities at the Winnipeg site with 100 percent excess heat. Figure 10 shows how the temperature outlines are produced when completing an expansion on the $\mathrm{CHP} / \mathrm{GCHP}$ hybrid system. The improved borehole arrangement used a square configuration was $10 \times 10$ boreholes with $7 \mathrm{~m}$ positioning for both sites. Appropriately, the best possible borehole depths, $60 \mathrm{~m}$ and $100 \mathrm{~m}$, were established for both the Ohio and Winnipeg locations. Although 20 percent of the surplus energy is dissipated, there is still sufficient additional energy to avoid drifting of the ground temperature for the Ohio site over the lifetime of the system. For the Winnipeg locale, an insignificant temperature drift has been detected, but all of the surplus CHP energy is being consumed.

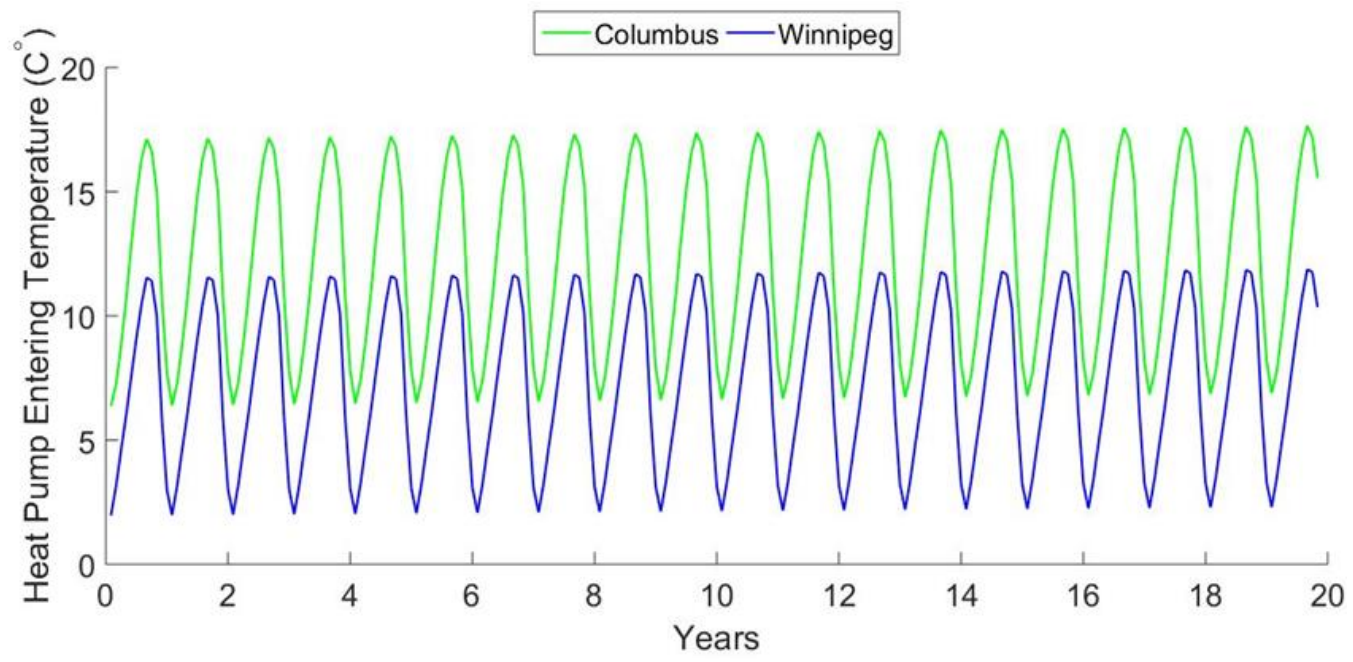

Figure 10. Hybrid GCHP heat pump entering fluid temperatures for a 20-year period.

\subsection{Reduction in Cost and $\mathrm{CO}_{2}$ Production}

Bar graphs in Figures 11 and 12 demonstrate the monthly cost advantage of the CHP/geothermal borehole system for Ohio and Winnipeg. Assuming all capacities are content with grid power, each graph evaluates an original monthly energy rate to the hybrid system rate that is improved. The life-cycle cost assessment assesses the value of the hybrid system as compared to using grid power for all structure capacities. Annual reserves are projected for a 20-year lifespan. While allowing for an annual energy inflation rate of 5\%, Figure 12 shows the annual rate for traditional power is determined by monthly cost calculation. Figure 12 also shows how totaling the monthly NG process plus adding an inflation rate of $3 \%$ for NG expenses explains how the annual functioning costs of the hybrid system are calculated for each year of the system's lifetime. The annual reserves are permitted over the lifetime of the investment assessment.

The annual savings are calculated on the assumption of a 5\% interest rate on loan, which is the current cost of each. Net present value (NPV) is generated when the hybrid system principal expenses are presumed to be acquired as an undesirable quantity, and these values are concise when the lifespan is introduced. The degree of interest that would drive the repayment time to be the complete lifespan requires a full 20 years to achieve a zero NPV, as the internal rate of return (IRR) is described for this situation. Primary investment costs are calculated with IRR.

Table 3: NPV and IRR calculations for the Ohio and Winnipeg hybrid system show the NPV and IRR calculations for two locations: Ohio and Canada, respectively. Appropriately, the IRR estimate for both sites is $17 \%$ and $20 \%$. These outcomes specify the cost-benefit of functioning in a location that is dominated by heating. 


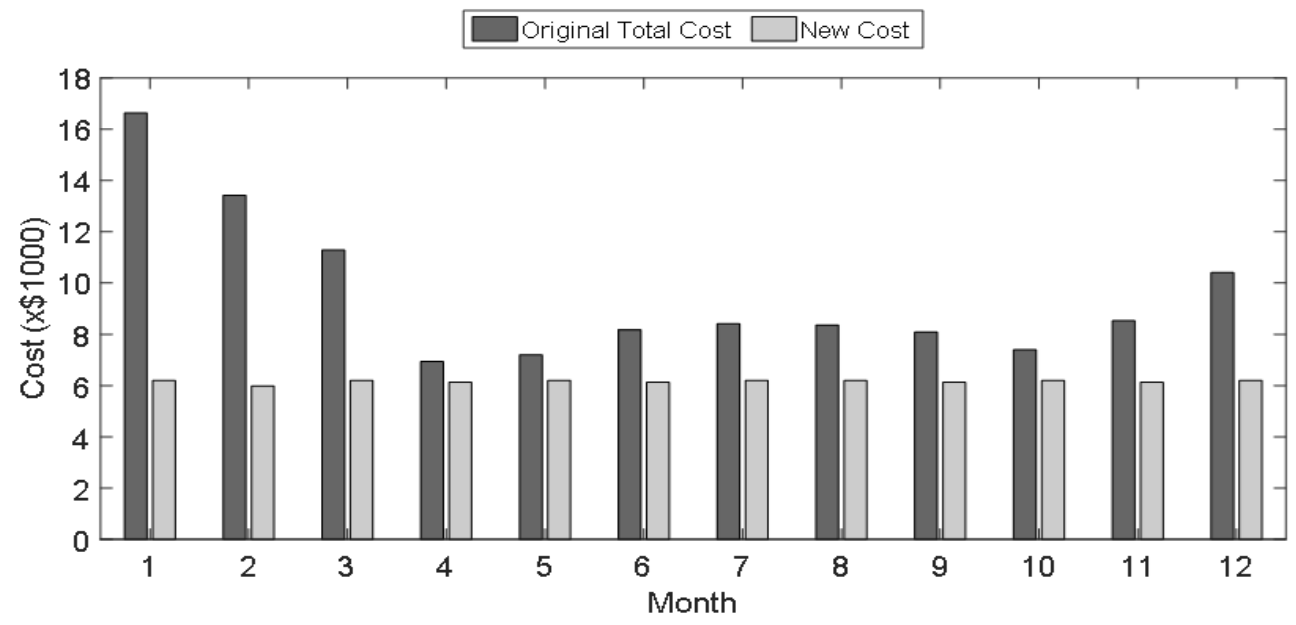

Figure 11. Original all-electric monthly energy costs compared to hybrid CHP/geothermal costs for Ohio.

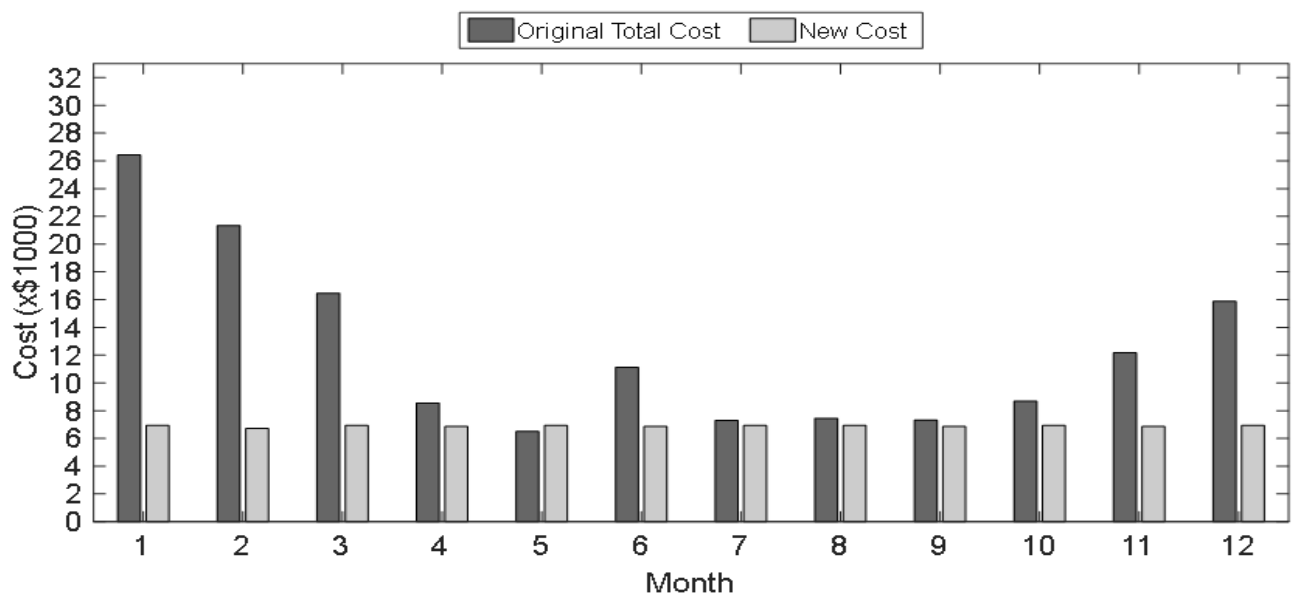

Figure 12. Original all-electric monthly energy costs compared to hybrid CHP/geothermal costs for Winnipeg.

Table 3. Net present value (NPV) and internal return rate (IRR) calculations for the hybrid system in Ohio and Winnipeg.

\begin{tabular}{ccc}
\hline & Ohio & Winnipeg \\
\hline Conventional Grid Power Cost (USD/year) & 115,310 USD & 115,310 USD \\
\hline Inflation Rate for Grid Power & $5 \%$ & $5 \%$ \\
\hline NG Cost for Hybrid System (USD/year) & 26,831 USD & 26,831 USD \\
\hline Inflation Rate for NG & $3 \%$ & $3 \%$ \\
\hline Initial Capital Cost & 827,240 USD & $1,211,200$ USD \\
\hline Loan Lifetime (years) & 20 & 20 \\
\hline Loan Interest Rate & $5 \%$ & $5 \%$ \\
\hline Net Present Value & $1,240,900$ USD & $3,097,200$ USD \\
\hline Internal Rate of Return (IRR) & $17 \%$ & $20 \%$ \\
\hline
\end{tabular}

$\mathrm{CO}_{2}$ production for the hybrid system comes from the NG burned by the $\mathrm{CHP}$ and from the purchased grid power. With the original all-electric system, $\mathrm{CO}_{2}$ is produced only by grid power. 
The hybrid system's $\mathrm{CO}_{2}$ reduction is $15 \%$ for Ohio and $30 \%$ for Canada. This model does not take into account $\mathrm{CO}_{2}$ generated when manufacturing the $\mathrm{CHP}$ and other hardware.

\section{Conclusions}

This work presents a design for a multi-family building hybrid CHP and GCHP system so that the electrical output of CHP satisfies the electrical load and the thermal output of CHP meets the demand for hot water. On the electrical side, batteries are used for storing and releasing electrical energy to better match the supply of CHP to the load. During times of high demand, grid power is used as a backup and any excess CHP electrical energy should be returned to the network during times of low demand. The heating and cooling loads from the building are provided by the GCHP. In a heating-dominated climate, excess heat from CHP that is not used for hot water is passed into the borehole system to balance heating and cooling loads and to prevent drifting of ground temperature.

The hybrid system was simulated using historical loads from a multi-family residence in Ohio, together with a GCHP model and dispatching algorithm for handling electrical and thermal energy flows and battery charging status. The simulation determines the power flow from the CHP to each system element and predicts the drift of ground temperature caused by any heating and cooling imbalance presented to the GCHP. Optimization is done to minimize the cost of an annual system, with the constraint that the net grid energy purchases are equal to the energy sold back to the grid (net-zero metering). Results are generated by operating the system in two locations: Columbus, Ohio, in the US, and Winnipeg in Canada.

Author Contributions: S.A., J.M., K.P.H. and R.E. performed the literature review, modelling, theoretical framework, and paper drafting. S.A. has performed an extensive analysis of the draft, experiment framework, and developed simulation models. S.A., J.M., K.P.H. and R.E. contributed towards the critical revision of the work. All authors have read and agreed to the published version of the manuscript.

Funding: The authors would like to express their gratitude to the Ministry of Education and the Deanship of Scientific Research, Najran University-Kingdom of Saudi Arabia for their financial and technical support under code number (code NU/ESCI/16/083).

Acknowledgments: The authors acknowledge thanks to the University of Dayton to carrying out this work.

Conflicts of Interest: The authors declare no conflict of interest.

\section{References}

1. Environmental News Network. ENERGY STAR's First Multifamily Properties Announced Today. Available online: https://www.enn.com/articles/48008 (accessed on 20 September 2020).

2. Pivo, G. Unequal access to energy efficiency in US multifamily rental housing: Opportunities to improve. Build. Res. Inf. 2014, 42, 551-573. [CrossRef]

3. Levinson, A.; Niemann, S. Energy use by apartment tenants when landlords pay for utilities. Resour. Energy Econ. 2004, 26, 51-75. [CrossRef]

4. American, T.; Economy, E.; Catherine, T. The Multifamily Energy Savings Project; ACEEE: Washington, DC, USA, 2015.

5. Raziei, A.; Hallinan, K.P.; Brecha, R.J. Clean energy utility for multifamily housing in a deregulated energy market. Energy Build 2016, 127, 806-817. [CrossRef]

6. Elhashmi, R.; Hallinan, K.P.; Chiasson, A.D. Low-energy opportunity for multi-family residences: A review and simulation-based study of a solar borehole thermal energy storage system. Energy 2020, 204, 117870. [CrossRef]

7. Darrow, K.; Tidball, R.; Wang, J.; Hampson, A. Catalog of CHP Technologies; U.S. Environmental Protection Agency (EPA) \& Combined Heat and Power Partnership (CHP): Washington DC, USA, 2015.

8. Electricity. Available online: http://www.eia.gov/electricity/ (accessed on 20 September 2020).

9. Cai, B.; Li, H.; Hu, Y.; Liu, L.; Huang, J.; Lazzaretto, A.; Zhang, G. Theoretical and experimental study of combined heat and power (CHP) system integrated with ground source heat pump (GSHP). Appl. Therm. Eng. 2017, 127, 16-27. [CrossRef] 
10. Kalam, A.; King, A.; Moret, E.; Weerasinghe, U. Combined heat and power systems: Economic and policy barriers to growth. Chem. Cent. J. 2012, 6, S3. [CrossRef] [PubMed]

11. Alqaed, S.; Hallinan, K. Developing a cost-optimal retrofit CHP system for multi-family buildings using historical demand. Int. J. Adv. Res. 2017, 5, 1786-1800. [CrossRef]

12. Perea, E.; Ruiz, N.; Cobelo, I.; Lizuain, Z.; Carrascal, A. A novel optimization algorithm for efficient economic dispatch of Combined Heat and Power devices. Energy Build. 2016, 111, 507-514. [CrossRef]

13. Yi, M.; Hongxing, Y.; Zhaohong, F. Study on hybrid ground-coupled heat pump systems. Energy Build. 2008, 40, 2028-2036. [CrossRef]

14. Yang, H.; Cui, P.; Fang, Z. Vertical-borehole ground-coupled heat pumps: A review of models and systems. Appl. Energy 2010, 87, 16-27. [CrossRef]

15. Yang, W.; Zhang, H.; Liang, X. Experimental performance evaluation and parametric study of a solar-ground source heat pump system operated in heating modes. Energy 2018, 149, 173-189. [CrossRef]

16. Chiasson, A.; Yavuzturk, C. Simulation of Hybrid Solar-Geothermal Heat Pump Systems. In Proceedings of the 39th Workshop on Geothermal Reservoir Engineering, Stanford, CA, USA, 24-26 February 2014.

17. Kottek, M.; Grieser, J.; Beck, C.; Rudolf, B.; Rubel, F. World Map of the Köppen-Geiger climate classification updated. Meteorol. Z. 2006, 15, 259-263. [CrossRef]

18. Weather Data Depot. Available online: http://www.weatherdatadepot.com/?gclid=CIm7wvKXuc0CFQ6maQ odL9wDIg (accessed on 20 September 2020).

19. Zhang, X.; Zhang, T.; Li, B.; Jiang, Y. Comparison of Four Methods for Borehole Heat Exchanger Sizing Subject to Thermal Response Test Parameter Estimation. Energies 2019, 12, 4067. [CrossRef]

20. Chiasson, A.D.; Elhashmi, R. Alternate Approach to the Calculation of Thermal Response Factors for Vertical Borehole Ground Heat Exchanger Arrays Using an Incomplete Bessel Function. In Proceedings of the IGSHPA Technical/Research Conference and Expo 2017, Denver, CO, USA, 14-16 March 2017.

21. National Grid. Combined Heat and Power (CHP): A Guide to Submitting CHP Applications for Incentives in Rhode Island; National Grid: New York, NY, USA, 2016.

22. Dotson, G.; Auel, E. The Buildings of Tomorrow Are Here Today; Centre for American Progress: Washington, DC, USA, 2015; pp. 1-6.

(C) 2020 by the authors. Licensee MDPI, Basel, Switzerland. This article is an open access article distributed under the terms and conditions of the Creative Commons Attribution (CC BY) license (http://creativecommons.org/licenses/by/4.0/). 